\title{
Injuries and Medical Conditions Among Kayakers Paddling in the Sea Environment
}

\author{
Colin Powell, BSc (tech), FHEA \\ From the Cardiff School of Health Sciences, University of Wales Institute, Cardiff, UK.
}

\begin{abstract}
Objective.-Directly experienced health impacts and the perception of health impacts affecting the wider community kayaking in the sea environment were assessed.

Methods.-Four hundred questionnaires were distributed at coastal launch sites in West Wales. One hundred and seventy-eight questionnaires were returned.

Results.-The majority of respondents had not received injuries or developed medical conditions as a result of kayaking in the sea. Among those who had directly encountered health impacts, problems with joints, tendons, and muscles were the most frequently reported injury. When asked what were the most common health impacts in general among those who kayak in the sea, 'sprains and pulled muscles' and 'cuts and abrasions' were the most frequently cited factors. The rank order of the 'most common injury or medical condition' and the 'most commonly injured part of the body' varied according to type of boat used and activity undertaken. This variation was evident in relation to direct experience of health impacts and the perception of injuries and medical conditions affecting other kayakers. Most respondents regarded injuries and medical conditions as uncommon and not serious and reported positive health effects from kayaking.

Conclusions.-Health impacts encountered by those kayaking in the sea reflect many of those identified in literature focusing upon other aspects of kayaking. Responses to questions regarding the most common injury or medical condition and the most common injury site vary according to type of boat used and activity undertaken. It is concluded that while there may be common demands placed upon paddlers using a variety of boats and participating in differing activities, it cannot be assumed that they are a homogeneous group. This has implications for the development of incident prevention strategies.
\end{abstract}

Key words: kayak, injury, sea kayak, medical condition, kayaker, paddle sport

\section{Introduction}

Kayaking in the sea includes a range of activities such as surfing, touring, playboating, and expeditions. These activities utilize a range of boats with differing characteristics and take place in environments posing specific demands.

While fatalities can be a consequence of kayaking incidents, ${ }^{1,2}$ death is relatively rare in white-water sport, ${ }^{3}$ and the incidence of injuries in aquatic sporting and recreational activities is low. ${ }^{4}$ In 2007 there were 6 fatalities among the estimated 340000 people kayaking in UK coastal waters. ${ }^{1}$ Actual injury rates are difficult to ascertain, as many incidents are likely to be unrecorded.

Corresponding author: Colin Powell, BSc (tech), FHEA, Cardiff School of Health Sciences, University of Wales Institute, Western Ave, CF5 2YB, Cardiff, UK (e-mail: cpowell@uwic.ac.uk).
The number of studies focusing specifically on injuries while kayaking in the sea environment appears to be limited. Research has been published that assesses the health impacts experienced by white-water river paddlers, long-distance paddlers, and participants in competitive kayaking activities. Aspects of these studies are of relevance to kayaking in the sea.

The literature $e^{5-13}$ identifies both acute and chronic conditions and that these conditions vary in their seriousness and significance with regard to long-term health. Kizer ${ }^{5}$ states that injuries linked to submersion, overuse, and trauma are the most common reported medical conditions. Conditions identified include blisters, ${ }^{5,6,13}$ contusions, ${ }^{6-8}$ lacerations and abrasions, ${ }^{6,13}$ muscle pain and sprains ${ }^{5,11-13}$ and dislocation of the shoulder. $^{5-8,13}$ A range of overuse syndromes are reported in the literature. ${ }^{5-11}$ These syndromes include 
tenosynovitis of wrist extensor tendons, flexor tendinitis, carpal tunnel syndrome, and forearm compartment syndrome. ${ }^{7}$ Other conditions identified include eye damage and sunburn from ultraviolet radiation ${ }^{6,7}$ and ear infections. ${ }^{6}$ Dislocation of the shoulder is the most common orthopedic injury identified. ${ }^{5-8,13}$

The most common injury sites appear to be the upper limbs and back; however, Schoen and Stano ${ }^{13}$ suggest that a rise in chronic chest and hip problems may be linked to increased 'playboat' activity. This study aims to investigate the perception, prevalence, and nature of reported injury and medical conditions among those using kayaks in the sea environment.

\section{Methodology}

A questionnaire focusing upon the nature and rates of injuries was distributed over a 1-year period on weekends and during school holidays. Respondents were asked to answer questions with reference to the main activity they undertook in the sea environment and the type of boat used. Participants' direct experience of health impacts can provide information on injuries and medical conditions. Additionally, an analysis of beliefs about the health impacts encountered by others can present an insight into collective knowledge and the social construct of injuries. ${ }^{14-16}$ Respondents were therefore asked questions relating to their personal experience of health impacts and their perception of injuries and medical conditions encountered by the wider group of people kayaking in the sea.

Questionnaire distribution took place at a range of launch sites in the Welsh coastal county of Pembrokeshire. Pembrokeshire was chosen because it is regarded as one of the primary coastal kayaking areas in the UK. The conditions and locations encountered in a small geographic area are varied, ranging from holiday beaches, harbors, and sheltered water to internationally known tidal races, overfalls, and exposed sea crossings. In addition to this, UK participants at the Anglesey Sea Kayak Symposium in North Wales were invited to participate in the study.

Typically, participants were approached when they were seen with a kayak, for example, while loading or unloading boats or resting on shore. Children under the age of 16 years were not included in the study. Paddlers using a wide range of kayak styles were targeted. Boats included 'surf' kayaks, 'playboats,' 'general-purpose' kayaks (gp), 'sea kayaks,' and 'sit-on' kayaks.

Participants were invited to take additional questionnaires to pass on to colleagues who kayaked in the sea. Four hundred questionnaires with accompanying 'Freepost' envelopes were handed out. The questionnaire

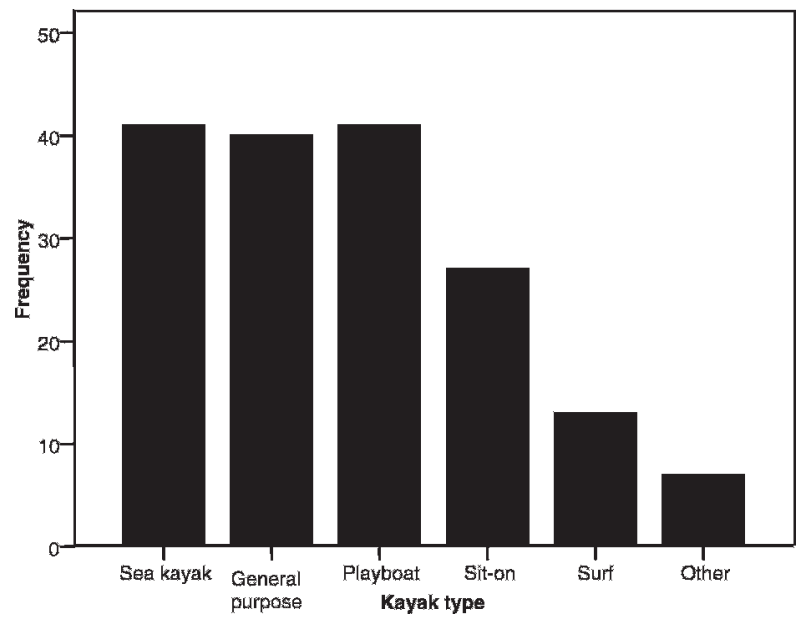

Figure 1. Kayak used for main activity.

assessed numerous variables; this limited the number of responses in certain categories. In general, response categories were not combined, as this would mask information. As a consequence of this design, it was not possible to use the $\chi^{2}$ test (or derivatives to assess correlation). The Fisher exact test was utilized as a test for independence between categorical variables.

\section{Results}

One hundred and seventy-eight completed questionnaires were returned. Of these, 5 were excluded from analysis because the respondents were under 16 years of age. The ages of the respondents ranged from 16 to 69 years, and the mean age of the sample was 37 years.

\section{PADDLING BEHAVIOR AND PADDLER CHARACTERISTICS}

The majority of the respondents reported that their main activity was 'surfing' $(N=64)$. This was followed by 'coastal touring' $(N=53)$ and 'recreational paddling' ( $N$ $=31$ ). These 3 categories accounted for $85 \%$ of the responses. A range of boats were used for these activities (Figure 1). 'Surfing' was the main activity among those who used 'playboats.' Those using gp kayaks were split among the activities of 'surfing,' 'recreational paddling,' and 'coastal touring.' 'Sit-on' kayak paddlers were mainly involved in 'coastal touring' and 'recreational paddling.' The main activity among those who used 'sea kayaks' was 'coastal touring.'

Most of the respondents $(N=125)$ stated that their paddling activity did not exceed half a day. The duration of activity varied according to the type of boat used and the activity. Compared with other groups, a greater proportion of those using 'sea kayaks' reported that 
Table 1. Perceived most common injury or condition among the wider kayaking group

\begin{tabular}{lr}
\hline Injury or medical condition & Frequency \\
\hline Cuts and abrasions & 33 \\
Bruises & 12 \\
Blisters & 19 \\
Painful joints or tendons & 19 \\
Sprains and pulled muscles & 34 \\
Dislocation & 2 \\
Concussion & 1 \\
Hypothermia & 5 \\
Near drowning & 3 \\
Sunburn & 20 \\
Painful or stiff back & 21 \\
Upset stomach & 1 \\
Other & 1 \\
Total & 171 \\
Missing & 2 \\
Total & 173 \\
\hline
\end{tabular}

activities typically lasted for over 4 hours. Thirty-nine percent of the 46 respondents who said their main activity was 'coastal touring' reported that activities tended to be over 4 hours long. This contrasts with $12 \%$ of the 60 respondents whose main activity was 'surfing.'

Paddling frequency varied greatly among participants. Fifty-five of the respondents reported paddling 20 or more times a year, while another 46 respondents reported paddling 1 to 5 times a year.

Table 2. Perceived most common injury or condition among the wider kayaking group/activity cross tabulation

\begin{tabular}{lrcr}
\hline & \multicolumn{3}{c}{ Activity } \\
\cline { 2 - 4 } Injury or medical condition & $\begin{array}{c}\text { Coastal } \\
\text { touring }\end{array}$ & $\begin{array}{c}\text { Recreational } \\
\text { paddling }\end{array}$ & Surfing \\
\hline Cuts and abrasions & 11 & 3 & 9 \\
Bruises & 0 & 2 & 8 \\
Blisters & 3 & 3 & 10 \\
Painful joints or tendons & 9 & 1 & 6 \\
Sprains and pulled muscles & 9 & 8 & 14 \\
Dislocation & 0 & 1 & 1 \\
Concussion & 0 & 1 & 0 \\
Hypothermia & 4 & 1 & 0 \\
Near drowning & 1 & 1 & 1 \\
Sunburn & 5 & 6 & 8 \\
Painful or stiff back & 9 & 4 & 6 \\
Upset stomach & 0 & 0 & 1 \\
Other & 1 & 0 & 0 \\
Total & 52 & 31 & 64 \\
\hline
\end{tabular}

Table 3. Summary of statistically significant differences between activities in relation to the perceived most common injury or condition among the wider kayaking group

\begin{tabular}{|c|c|c|c|}
\hline $\begin{array}{l}\text { Injury or } \\
\text { medical } \\
\text { condition }\end{array}$ & & Activity & $\begin{array}{c}\text { Fisher } \\
\text { exact test } \\
P \text {-value } \\
(2 \text {-sided })\end{array}$ \\
\hline Bruises & Surfing & Coastal touring & $<.01$ \\
\hline Hypothermia & Surfing & Coastal touring & $<.05$ \\
\hline
\end{tabular}

The number of years for which participants had been involved in paddling in the sea was wide ranging. A larger proportion of those using 'sea kayaks' and 'playboats' reported having paddled in the sea for more years than those paddling gp boats and 'sit-on' kayaks. Eighty-six percent of those involved in 'recreational paddling' had been paddling for fewer than 5 years; this compares with $65 \%$ for 'surfing' and $53 \%$ for 'coastal touring.'

A higher percentage of respondents who used 'sit-on' kayaks and gp kayaks regarded themselves as 'beginners' than did those using 'sea kayaks' and 'playboats.' The majority of respondents who defined themselves as 'expert' used 'sea kayaks' or 'playboats.'

\section{INJURIES AND MEDICAL CONDITIONS AFFECTING THE WIDER GROUP KAYAKING IN THE SEA}

Participants were asked questions relating to what they thought were the most common health impacts among those who kayak in the sea (Table 1). 'Sprains and pulled muscles' and 'cuts and abrasions' were quoted as the most common injuries or medical conditions. These were followed by a range of injuries, including 'painful or stiff back,' 'sunburn,' 'painful joints or tendons,' 'blisters,' and 'bruises.' The remaining factors combined accounted for $8 \%$ of the responses.

Further analysis was conducted to determine variation according to categories of activity (Table 2). 'Coastal touring,' 'recreational paddling,' and 'surfing' accounted for $86 \%$ of the reported activities. In view of this, it was felt that the remainder of the activities did not provide sufficient numbers of cases to enable meaningful analysis.

The rank order of the most common injuries or conditions varies according to activity. A number of statistically significant differences were identified between activities in relation to the response to the 'most common injury or medical condition' (Table 3). Cross tabulating perceived most common injury with kayak indicates that there are similarities in response to factors 
Table 4. Summary of statistically significant differences between kayak used and the perceived most common injury or condition among the wider kayaking group

\begin{tabular}{cllc}
\hline $\begin{array}{c}\text { Injury or medical } \\
\text { condition }\end{array}$ & Kayak & $\begin{array}{c}\text { Fisher exact } \\
\text { test } P \text {-value } \\
(2 \text {-sided })\end{array}$ \\
\hline $\begin{array}{llll}\text { Painful joints or tendons } \\
\text { Painful joints or tendons }\end{array}$ & Playboat & Sea kayak & $<.05$ \\
& & Sea kayak & $<.01$ \\
\hline
\end{tabular}

such as 'cuts and abrasions' and 'painful and stiff back.' However, a larger proportion of those using 'sea kayaks' identified 'painful joints and tendons' as 'the most common injury or medical condition' than did those using 'playboats' or 'sit-on' kayaks (Table 4).

The back was identified as the single most commonly injured part of the body, accounting for $19 \%$ of the responses; this was followed by hands (13\%), shoulders $(12 \%)$, and the head $(11 \%)$. Individual sites on the upper limbs combined with 'upper limbs multiple site' accounted for $48 \%$ of the responses (Table 5).

Differences were observed between categories when cross tabulating the perceived most commonly injured part of the body among the wider kayaking group with type of kayak used (Tables 6 and 7). Cross tabulating activities with the perceived most commonly injured part of the body among the wider kayaking group demonstrates differences in the response patterns (Tables 8 and 9).

The majority of respondents $(N=141)$ regarded most injuries and medical conditions associated with kayaking in the sea as not serious; of this group, 101 respondents

Table 5. Perceived most commonly injured part of the body among the wider kayaking group

\begin{tabular}{lc}
\hline Most commonly injured part of the body & Frequency \\
\hline & \\
Hand & 22 \\
Wrist & 8 \\
Arms & 12 \\
Shoulder & 20 \\
Back & 31 \\
Chest & 1 \\
Head & 18 \\
Neck & 1 \\
Other & 13 \\
Upper limb multiple site & 17 \\
Back and other site & 16 \\
Other multiple site & 5 \\
Total & 164 \\
Missing & 9 \\
Total & 173 \\
\hline
\end{tabular}

also regarded the occurrence as being uncommon (Table 10). Of the 25 respondents who regarded most injuries and medical conditions as serious, a minority $(N$ $=3$ ) regarded the occurrence as common.

\section{SELF-REPORTED INJURIES}

Approximately $35 \%(N=60)$ of the respondents indicated that they had received injuries or developed medical conditions as a result of kayaking in the sea (Table 11). Of these 60 respondents, 21 stated that they had received medical treatment. Seven respondents stated that their injuries or conditions resulted in time off work, college, or school; 3 respondents stated that the injuries or conditions had resulted in a change in lifestyle. Twenty-seven of the respondents indicated that injuries or medical conditions had resulted in them taking time off kayaking. Four respondents regarded their health impacts as serious.

The proportion of those using 'sit-on' kayaks who experienced injuries and medical conditions was lower than that of those using other categories of boats. This may reflect differences in the characteristics of the boat and paddlers, the nature of activity, or lower levels of exposure, as the number of years of participation of this group tended to be relatively low. Problems associated with 'joints, tendons, and muscles' were the most common identified injury or medical condition. This accounted for $37 \%$ of the responses (Figure 2). When considering the seriousness of health impacts, 'joints, tendons, and muscles' was seen to be the major issue and was cited by $30 \%$ of those who had received injuries or developed medical conditions (Table 12).

As a result of the small number of cases, there is a need for caution when subdividing the data relating to injuries and medical conditions encountered. While mindful of this, a number of issues are noted that indicate different injury patterns (Table 13). A greater proportion of those who paddled 'sea kayaks' identified problems with 'joints, tendons, and muscles' as the most common injury or medical condition than did those who paddled 'playboats.'

While only a small group, 3 out of the 5 people using 'sit-on' kayaks identified 'impact to the head' as the most common injury; this was not identified by the users of other categories of kayak. While no respondents whose main activity was 'coastal touring' identified 'bruises' as the most common injury encountered, this factor was identified by 6 people from the 'surfing' category. The Fisher exact test indicates that this is a statistically significant difference $(P<.05,2$-sided).

There were statistically significant differences between what was regarded as the most serious injuries or medical 
Table 6. Perceived most commonly injured part of the body among the wider kayaking group/kayak used cross tabulation

\begin{tabular}{|c|c|c|c|c|c|c|c|}
\hline \multirow{2}{*}{$\begin{array}{c}\text { Most commonly injured } \\
\text { part of the body }\end{array}$} & \multicolumn{7}{|c|}{ Kayak } \\
\hline & Sea kayak & General purpose & Playboat & Sit-on & Surf kayak & Other & Total \\
\hline Hand & 3 & 3 & 7 & 4 & 2 & 2 & 21 \\
\hline Wrist & 6 & 1 & 0 & 0 & 1 & 0 & 8 \\
\hline Arms & 1 & 5 & 5 & 1 & 0 & 0 & 12 \\
\hline Shoulder & 6 & 4 & 7 & 2 & 0 & 1 & 20 \\
\hline Back & 8 & 8 & 5 & 7 & 1 & 1 & 30 \\
\hline Head & 3 & 4 & 1 & 9 & 1 & 0 & 18 \\
\hline Neck & 0 & 1 & 0 & 0 & 0 & 0 & 1 \\
\hline Upper limb multiple site & 4 & 4 & 3 & 1 & 3 & 1 & 16 \\
\hline Back and other site & 4 & 3 & 6 & 0 & 3 & 0 & 16 \\
\hline Other multiple site & 0 & 1 & 3 & 1 & 0 & 0 & 5 \\
\hline Other & 4 & 3 & 4 & 1 & 0 & 1 & 13 \\
\hline Total & 39 & 37 & 41 & 26 & 11 & 6 & 160 \\
\hline
\end{tabular}

condition encountered according to the type of boat used (Table 14).

Compared to those using 'playboats,' a greater proportion of those using 'sea kayaks' identified 'joints, tendons, and muscles' as being associated with the most serious injury or medical condition personally experienced. Whereas 'cuts and abrasions' and 'bruises' as a combined category was identified as the most serious injury or medical condition encountered by 7 of the 19 using 'playboats,' this factor was not identified by those using 'sea kayaks.'

\section{POSITIVE HEALTH EFFECTS}

Ninety-six percent of the respondents $(N=166)$ stated that they thought that there were positive health effects associated with kayaking in the sea. Of these, $46 \%$ felt that there were both physical and psychological benefits to kayaking: as one respondent stated, "Good all round exercise ... sharpens your senses and good for the soul!"

Table 7. Summary of statistically significant differences between kayak used in relation to the perceived most commonly injured part of the body among the wider kayaking group

\begin{tabular}{|c|c|c|c|}
\hline $\begin{array}{c}\text { Most } \\
\text { commonly } \\
\text { injured part } \\
\text { of the body }\end{array}$ & & Kayak & $\begin{array}{l}\text { Fisher } \\
\text { exact test } \\
\text { P-value } \\
(2 \text {-sided })\end{array}$ \\
\hline Head & Sit-on & General purpose & $<.05$ \\
\hline Head & Sit-on & Sea kayak & $<.01$ \\
\hline Head & Sit-on & Playboat & $<.01$ \\
\hline Wrist & Sea kayak & Playboat & $<.05$ \\
\hline
\end{tabular}

\section{Discussion}

The type of boat used, the activities undertaken, the duration and frequency of activity, the levels of experience, and self-reported ability vary among those paddling kayaks in the sea. These factors may influence both the direct experience of health impacts and the perception of the nature and likelihood of injuries and medical conditions affecting paddlers in general.

The majority of respondents reported that they had not received injuries or developed medical conditions as a result of kayaking in the sea. Most respondents regarded injuries and medical conditions as uncommon and not serious. This view was reflected by those who had experienced injuries and medical conditions. This

Table 8. Perceived most commonly injured part of the body among the wider kayaking group/activity cross tabulation

\begin{tabular}{lrcr}
\hline & \multicolumn{3}{c}{ Activity } \\
\cline { 2 - 4 } $\begin{array}{c}\text { Most commonly injured } \\
\text { part of the body }\end{array}$ & $\begin{array}{c}\text { Coastal } \\
\text { touring }\end{array}$ & $\begin{array}{c}\text { Recreational } \\
\text { paddling }\end{array}$ & Surfing \\
\hline Hand & 4 & 2 & 10 \\
Wrist & 4 & 0 & 2 \\
Arms & 2 & 2 & 5 \\
Shoulder & 8 & 3 & 9 \\
Back & 11 & 8 & 8 \\
Head & 8 & 6 & 3 \\
Neck & 1 & 0 & 0 \\
Other & 6 & 2 & 4 \\
Upper limb multiple site & 1 & 3 & 8 \\
Back and other site & 5 & 2 & 9 \\
Other multiple site & 0 & 1 & 3 \\
Total & 50 & 29 & 61 \\
\hline
\end{tabular}


Table 9. Summary of statistically significant differences between activities in relation to the perceived most commonly injured part of the body among the wider kayaking group

\begin{tabular}{|c|c|c|c|}
\hline $\begin{array}{c}\text { Most } \\
\text { commonly } \\
\text { injured part } \\
\text { of the body }\end{array}$ & & Activity & $\begin{array}{l}\text { Fisher } \\
\text { exact test } \\
P \text {-value } \\
\text { (2-sided) }\end{array}$ \\
\hline $\begin{array}{l}\text { Upper limb } \\
\text { multiple site }\end{array}$ & Surfing & Coastal touring & $<.05$ \\
\hline Head & Surfing & Recreational paddling & $<.05$ \\
\hline
\end{tabular}

supports the findings of previous studies ${ }^{5,11}$ that the majority of injuries in kayaking are not serious.

When commenting upon health impacts affecting those kayaking in the sea in general, the back was identified as the most common part of the body injured. Injuries linked to the back may stem from both paddling activities and lifting and carrying. ${ }^{9}$ The upper limbs were seen to be common injury sites; this concurs with riverbased studies. ${ }^{8,13}$

When asked what was the most common injury among the wider group kayaking in the sea, 'cuts and abrasions' was a frequently identified response category. 'Cuts and abrasions' was not a major response category among those who had directly experienced health impacts. It may be the case that significance as well as frequency of occurrence is being considered when assessing directly experienced health impacts. The differential views of injuries affecting one's self and injuries affecting others may reflect knowledge based upon direct experience, experience of others injuries, and socially determined knowledge linked to activities. Such information may influence individual risk management strategies and therefore is of relevance to prevention initiatives.

Responses differed according to the type of activity and the type of boat used. This supports the view of Schoen and Stano ${ }^{13}$ that the levels and nature of reported injury are linked to activities and the types of boat paddled. Factors influencing injury can be illustrated by suggesting why only $2 \%$ of those using 'playboats'

Table 10. Perception of seriousness of injuries/frequency of occurrence cross tabulation

\begin{tabular}{lrcc}
\hline & \multicolumn{2}{c}{$\begin{array}{c}\text { Injuries and conditions seen as } \\
\text { common/uncommon }\end{array}$} \\
\cline { 2 - 4 } $\begin{array}{l}\text { Are most injuries } \\
\text { serious/not serious }\end{array}$ & Common & Uncommon & Total \\
\hline Serious & 3 & 22 & 25 \\
Not serious & 40 & 101 & 141 \\
Total & 43 & 123 & 166 \\
\hline
\end{tabular}

Table 11. Kayak used/experienced injuries or conditions from kayaking in the sea cross tabulation

\begin{tabular}{lccc}
\hline & \multicolumn{3}{c}{$\begin{array}{c}\text { Experienced injuries or conditions } \\
\text { Kayak kayaking in the sea }\end{array}$} \\
\cline { 2 - 4 } $\begin{array}{l}\text { froin activity } \\
\text { main }\end{array}$ & Yes & No & Total \\
\hline Sea kayak & 17 & 21 & 38 \\
General purpose & 13 & 25 & 38 \\
Playboat & 20 & 21 & 41 \\
Sit-on & 4 & 22 & 26 \\
Surf & 4 & 9 & 13 \\
Other & 2 & 5 & 7 \\
Total & 60 & 103 & 163 \\
\hline
\end{tabular}

identified the head as being the most common part of the body injured, compared to $35 \%$ of those using 'sit-on' kayaks. This difference could be due to a range of variables including skill level, experience, the use of protective helmets, and differences in the dynamics of capsize of a 'sit-in' and a 'sit-on' boat. Hence, individual characteristics, levels of exposure, boat-specific characteristics, norms and practices associated with activities, and the specific demands of activities may be intertwined in such a way as to lead to differing experiences and perceptions of health impacts.

Most studies of injuries and medical conditions in kayaking tend to focus on negative outcomes. In this study, participants were asked if they thought there were positive health effects associated with kayaking. Ninetysix percent of the respondents gave a positive response to this question and reported both physiological and psychological benefits. This response may represent and reinforce commitment to the activity and may enable acceptance of the possibility of injury.

A number of weaknesses are present in this study. The subdividing of data according to activity, type of boat used, and those who had encountered health impacts reduced the number of cases in categories and limited statistical analysis. The significance of differences in response patterns was determined using the Fisher exact test. The repeated use of this test increased the likelihood of returning a statistically significant result by chance. In view of this, while it is acceptable to assume that there are statistically significant differences between broad categories of variables, caution needs to be taken in relation to assuming differences between individual factors.

Recall bias may have influenced responses with either recent or personally significant events that are not necessarily representative but that come more easily to mind. Additionally, certain health impacts may be regarded as so regular and minor that they are not 


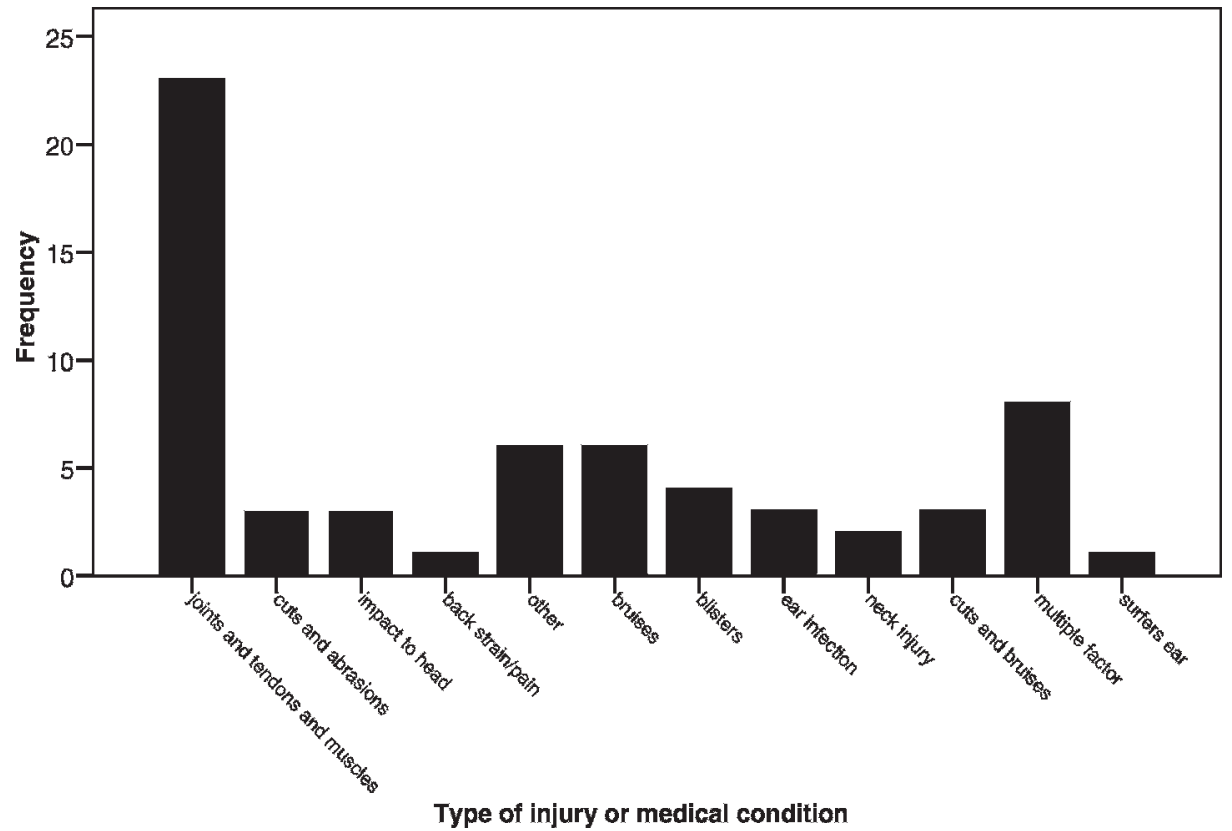

Figure 2. Most common injury or condition personally encountered.

reported. The data presented do not provide detailed information on frequency of occurrence or whether injuries and medical conditions are acute or chronic in onset. These issues could be addressed by the use of diaries to record incidents and health impacts.

Positive affective responses to kayaking may be influencing participants' views of the risks associated with the activity. Losses and potential losses may be downplayed to enable the justification for continued participation. Furthermore, some who had encountered problems may have left the activity, and so serious

Table 12. The most serious injury or medical condition experienced

\begin{tabular}{lc}
\hline Injury or medical condition & Frequency \\
\hline Shoulder dislocation & 4 \\
Joints, tendons, and muscles & 17 \\
Cuts and abrasions & 5 \\
Impact on head & 3 \\
Back strain/pain & 3 \\
Other & 6 \\
Bruises & 6 \\
Blisters & 1 \\
Ear infection & 2 \\
Neck injury & 3 \\
Cuts and bruises & 1 \\
Multiple factor & 4 \\
Surfer's ear & 2 \\
Total & 57 \\
\hline
\end{tabular}

incidents may be underreported. The number of years of paddling varied according to activity and type of boat used. Differences in response between categories may reflect levels of exposure, the age profile of respondents, and aspects of the aging process.

It is not possible to accurately determine the size of the population kayaking in the sea; therefore, there is a need for caution when considering the representativeness of the sample. This may be further compromised by a sampling bias. Sampling tended to occur on weekends and during holiday periods; therefore, people who paddle during the working week may be underrepresented. The distribution of questionnaires at a sea kayak symposium may have resulted in the overinclusion of experienced and committed sea kayak paddlers. Furthermore, asking

Table 13. Summary of statistically significant differences between kayak used and the most common injury or medical condition experienced

\begin{tabular}{llll}
\hline $\begin{array}{c}\text { Most common } \\
\text { injury or medical } \\
\begin{array}{c}\text { condition } \\
\text { experienced }\end{array}\end{array}$ & Kayak used & $\begin{array}{c}\text { Fisher } \\
\text { exact test } \\
\text { P-value } \\
(2 \text {-sided })\end{array}$ \\
\hline Bruises & Playboat & Sea kayak & $<.05$ \\
Impact to head & Sit-on & Playboat & $<.01$ \\
Impact to head & Sit-on & General purpose & $<.05$ \\
Impact to head & Sit-on & Sea kayak & $<.01$ \\
$\begin{array}{c}\text { Joints, tendons, and } \\
\text { muscles }\end{array}$ & Playboat & Sea kayak & $<.05$ \\
\hline
\end{tabular}


Table 14. Summary of statistically significant differences between kayak used in relation to the most serious injury or condition experienced

\begin{tabular}{|c|c|c|}
\hline $\begin{array}{c}\text { Most serious } \\
\text { injury or } \\
\text { medical condition } \\
\text { experienced }\end{array}$ & Kayak & $\begin{array}{c}\text { Fisher } \\
\text { exact test } \\
P \text {-value } \\
\text { (2-sided) }\end{array}$ \\
\hline
\end{tabular}

Cuts, abrasions, and bruises

Joints, tendons, and muscles

Sea kayak Playboat $\quad<.01$

Sea kayak Playboat $<.01$

participants to pass questionnaires to colleagues would have resulted in overrepresentation from groups with social networks.

Respondents may be using a range of boats and engaging in a variety of activities in the sea and other environments. Wider kayaking activities may influence experience and perception of injuries and medical conditions in the sea environment.

\section{Conclusions}

While the majority of respondents indicated that they had not received injuries or developed medical conditions as a result of kayaking in the sea, those health impacts identified reflect the findings of research focusing upon other aspects of kayaking. Most respondents regarded injuries and medical conditions as uncommon and not serious and reported positive health effects from kayaking. What was seen as the 'most common injury or medical condition' and the 'most commonly injured part of the body' varied according to type of boat used and activity undertaken.

People who kayak in the sea differ in terms of age, activity, boat use, experience, skill level, duration and frequency of participation, and environments encountered. The significance and nature of injuries and medical conditions and the associated causal factors may vary according to these characteristics.

Even though there may be common demands placed upon paddlers using a variety of boats and participating in differing activities, it cannot be assumed that they are a homogeneous group. Prevention strategies need to be sensitive to such issues to ensure the appropriate design and targeting of initiatives.

\section{Acknowledgments}

Dr Lalage Sanders, Dr Keith Morris, and Professor Adrian Peters of UWIC are acknowledged for support in the analysis of data.

\section{References}

1. Maritime and Coast Guard Agency. UK Maritime Leisure Sector: Facts and Figures 2007. MCA. Southampton; 2008.

2. American Canoe Association. Critical Judgement. II. Understanding and Preventing Canoe and Kayak Fatalities 1996-2002. Springfield, VA: American Canoe Association; 2004.

3. Fiore DC. Injuries associated with white water rafting and kayaking. Wilderness Environ Med. 2003;14:255-260.

4. Chalmers JC, Morrison L. Epidemiology of non-submersion injuries in aquatic sporting and recreational activities. Sports Med. 2003;33:745-770.

5. Kizer WK. Medical aspects of white-water kayaking. Physician Sports Med. 1987;15:128-137.

6. Weiss EA. Whitewater medicine. J Wilderness Med. 1991; 2:245-252.

7. Berglund B, McKenzie D. Injuries in canoeing and kayaking. In: Renstrom PAFH, ed. Clinical Practice of Sports Injury Prevention and Care. Vol 5. London, UK: Blackwell Scientific Publications; 1994.

8. Fiore DC, Houston JD. Injuries in white water kayaking. Br J Sports Med. 2001;35:235-241.

9. Hagman G, Rijke AM, Mars M. Shoulder pathonatomy in marathon kayakers. Br J Sports Med. 2004;38:413-417.

10. du Toit P, Sole C, Bowerbank P, Noakes TD. Incidence and causes of tenosynovitis of the wrist extensors in long distance paddle canoeists. Br J Sports Med. 1999;33:105109.

11. Krupnick JE, Cox RD, Summers RL. Injuries sustained during competitive white-water paddling: a survey of athletes in the 1996 Olympic trials. Wilderness Environ Med. 1998;9:14-18.

12. Kameyama O, Shibano K, Kawakita H, Ogawa R, Kumamoto M. Medical check of competitive canoeists. J Orthop Sci. 1999;4:243-249.

13. Schoen RG, Stano MJ. Year 2000 Whitewater Injury Survey. J Wilderness Environ Med. 2002;13:119-124.

14. Scherer CW, Cho H. A social network contagion theory of risk perception. Risk Anal. 2003;23:261-267.

15. Albert E. Dealing with danger. Int Rev Sociology Sport. 1999;34:157-171.

16. Halpern-Felsher BL, Millstein SG, Ellen JM, Adler NE, Tschann JM, Biehl M. The role of behavioural experience in judging risk. Health Psychol. 2001;20:120-126. 